\title{
A New Dental Superalloy System: II. Mechanical Properties
}

\author{
HAMDI MOHAMMED* and KAMAL ASGAR \\ School of Dentistry, University of Michigan, Ann Arbor, Michigan 48104 USA
}

Cobalt-base alloys strengthened by intermetallic compounds of tantalum were prepared and tested. Some of the alloys were stronger and more ductile than conventional base-metal alloys.

Theoretical considerations that lead to the design of strong and ductile cobalt $(\mathrm{Co})$ base alloys were discussed in part I of this series of articles. ${ }^{1}$

It was hypothesized that the composition 40 Co-30 nickel $(\mathrm{Ni})-30$ chromium $(\mathrm{Cr})$ is an acceptable compromise for the requirements of an alloy base. It also was found that tantalum (Ta) may have the qualities that are acceptable for an additional element; it reacts with Co to form intermetallic compounds that should produce a strong and ductile alloy.

The purpose of this investigation was to test the validity of this hypotheses. Alloys that were designed according to the ideas presented in part I were prepared and the mechanical properties of these alloys were tested.

\section{Materials and Methods}

The compositions of the alloys that were prepared in this study are found in the table. The metals used in these compositions were high purity metals with more than 99.9\% pure elements. Co and Ni were supplied in the form of small shots. $\mathrm{Cr}$ was supplied in sheet form and was crushed to smaller pieces $(2 \times 2 \mathrm{~mm})$. Ta was provided by thin wires that were cut to shorter pieces $(2 \mathrm{~mm})$. The ternary alloy elements,

Based on a dissertation submitted in partial fulfillment of the $\mathrm{PhD}$ degree in dental materials and engineering materials at the University of Michigan, 1971.

Part II was presented at the 50th general meeting of the IADR, Las Vegas, Nev, 1972.

Received for publication May 14, 1972.

* Present address: University of Connecticut, Health Center, School of Dental Medicine, Farmington, Conn 06032 .
$40 \mathrm{Co}-30 \mathrm{Ni}-30 \mathrm{Cr}$, were melted in an argon (Ar) atmosphere to a clean mirror surface. Then, Ta (melting point, $5425 \mathrm{~F}$ ) was added. Ta dissolved rapidly in the ternary alloy. The quaternary alloy was remelted under Ar for homogenization. The alloy then was heated to its casting temperature $(\sim 2750 \mathrm{~F})$; it was cast by use of a centrifugal induction furnace that had a vacuum system.

Because horizontal spruing produces less porous tensile specimens than vertical spruing, ${ }^{2}$ the former technique was modified and used in this study. A special metal mold was designed to furnish wax patterns for the tensile testing specimens. The mold can supply the tensile specimen, feed the sprue and riser, and vent the sprue and riser; the sprue base is readily assembled. The metal mold is shown in Figure 1. The dimensions of the tensile bar are those specified by American Dental Association Specification No. 14 for Co alloys. ${ }^{3}$

Wax patterns were invested in a phosphate-bonded investment. $\dagger$ The investment was heated to $1,800 \mathrm{~F}$ and it was heatsoaked for one hour before the castings were made.

Tensile properties were determined by use of a universal testing machine and a strain gauge extensometer. + The $0.2 \%$ offset yield strength, ultimate tensile strength, elongation, and modulus of elasticity were determined in a conventional manner. All tensile property values were the average of four specimens from each alloy.

Microhardness was determined by use of a microhardness tester, $\S$ a Knoop indenter, $\mid$ and a $500 \mathrm{gm}$ load. The specimens for

\footnotetext{
t Hydrovest investment, Whip-Mix Corp., Louisville, Ky.

I Instron Corporation, Canton, Mass.

$\$$ Tukon, Wilson Instrument Division of American Chain \& Cable, New York, NY.

II Knoop, Wilson Instrument Division of American Chain \& Cable, New York, NY.
} 
TABLE

\begin{tabular}{|c|c|c|c|c|}
\hline \multirow{3}{*}{$\begin{array}{c}\text { Alloy } \\
\text { Designation }\end{array}$} & \multicolumn{4}{|c|}{ Composition $(\%)$} \\
\hline & & $A$ & & $B$ \\
\hline & $\mathrm{Co}$ & $\mathrm{Cr}$ & $\mathrm{Ni}$ & $\mathrm{Ta}$ \\
\hline$A_{1} B_{1}$ & 40.0 & 30.0 & 30.0 & 0.0 \\
\hline$A_{2} B_{2}$ & 39.2 & 29.4 & 29.4 & 2.0 \\
\hline$A_{3} B_{3}$ & 38.4 & 28.8 & 28.8 & 3.9 \\
\hline$A_{4} B_{4}$ & 38.1 & 28.6 & 28.6 & 4.8 \\
\hline$A_{5} B_{5}$ & 37.7 & 28.3 & 28.3 & 5.7 \\
\hline$A_{6} B_{6}$ & 37.0 & 27.8 & 27.8 & 7.4 \\
\hline$A_{7} B_{7}$ & 36.3 & 27.3 & 27.3 & 9.1 \\
\hline$A_{8} B_{8}$ & 35.7 & 26.8 & 26.8 & 10.7 \\
\hline$A_{9} B_{9}$ & 35.1 & 26.3 & 26.3 & 12.3 \\
\hline$A_{10} B_{10}$ & 34.9 & 26.2 & 26.2 & 12.7 \\
\hline$A_{11} B_{11}$ & 34.8 & 26.1 & 26.1 & 13.0 \\
\hline$A_{12} B_{12}$ & 34.6 & 26.0 & 26.0 & 13.4 \\
\hline$A_{13} B_{13}$ & 34.5 & 25.9 & 25.9 & 13.8 \\
\hline$A_{14} B_{14}$ & 33.9 & 25.4 & 25.4 & 14.2 \\
\hline$A_{15} B_{15}$ & 33.3 & 25.0 & 25.0 & 16.7 \\
\hline
\end{tabular}

microhardness were longitudinal sections from test bars that were polished with conventional metallurgical procedures.

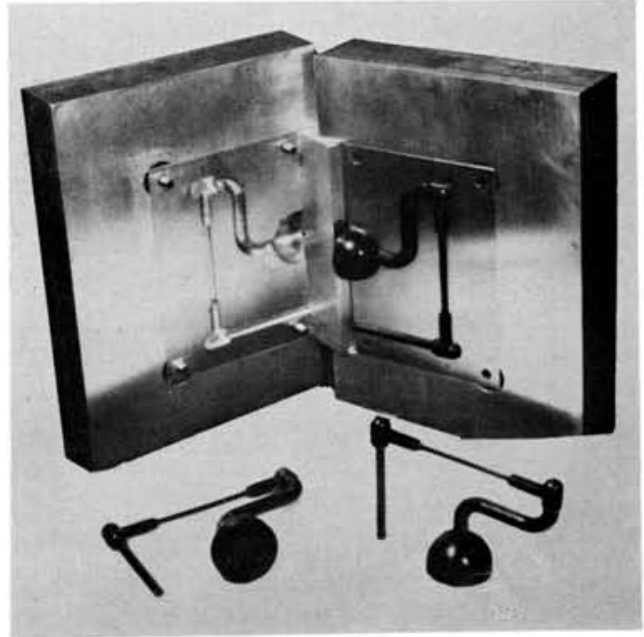

FIG 1.-Metal mold and tensile specimen wax pattern.

\section{Results}

ElONGATION:-The mean elongation values of the prepared alloys are plotted in a bar graph (Figure 2). The solid line at the

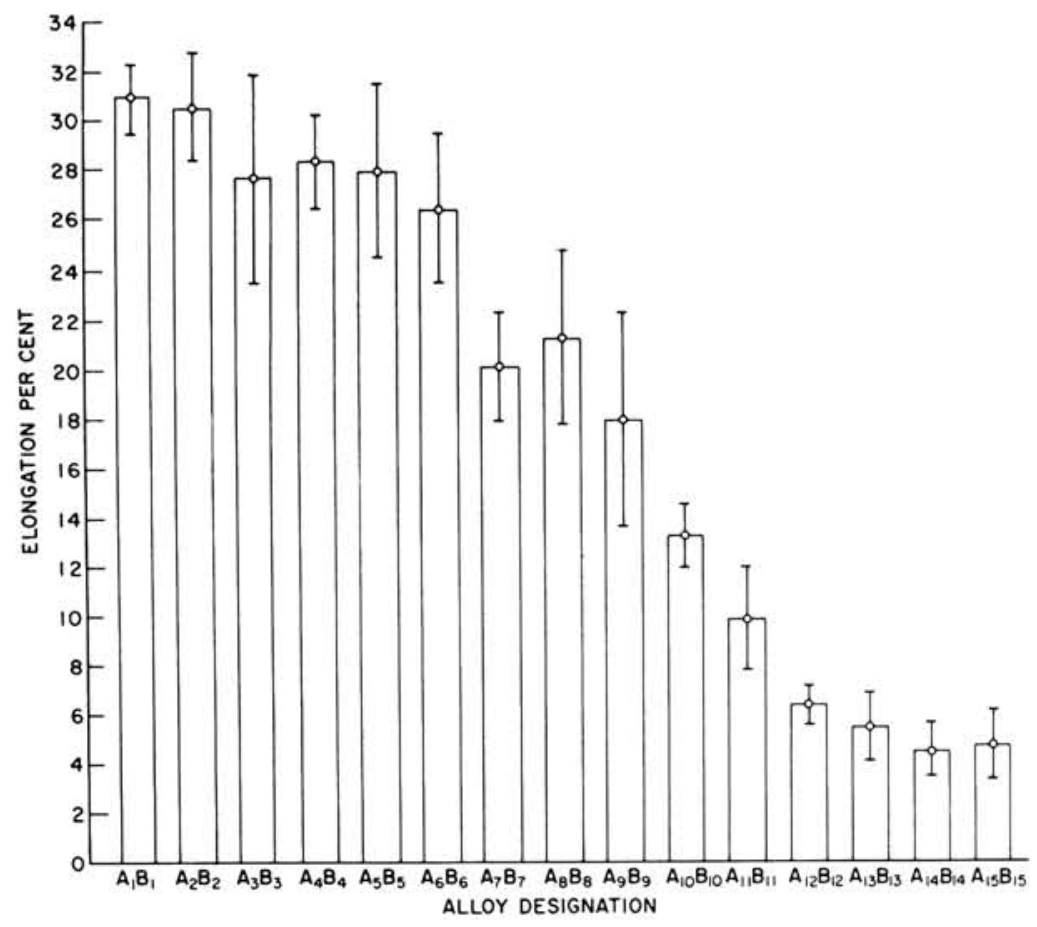

FIG 2.-Effect of alloy composition on ductility. 
top of each bar represents the $95 \%$ confidence interval for the respective alloy and it extends for a distance that corresponds to 6.36 standard errors. ${ }^{4}$

The elongation decreased with Ta concentration from $30.9 \%$ for the alloy base $A_{1} B_{1}$ that had no Ta to $4.7 \%$ for the alloy $A_{15} B_{15}$ that had $16.7 \%$ Ta. When the Ta concentration was increased in increments of $2 \mathrm{gm} / 100 \mathrm{gm}$ of the alloy base, the elongation decreased gradually. For example, when the $\mathrm{Ta}$ concentration was increased from $10.7 \%$ in alloy $A_{8} B_{8}$ to $12.3 \%$ in alloy $A_{9} B_{9}$, the elongation was decreased from 21.3 to $18.0 \%$. This gradual response of ductility to $\mathrm{Ta}$ addition was true for alloys $A_{1} B_{1}$ to $\mathrm{A}_{9} \mathrm{~B}_{9}$. When the Ta concentrations was increased from $12.3 \%$ in alloy $A_{9} B_{9}$ to $13.8 \%$ in alloy $A_{13} B_{13}$, the elongation decreased from 18.0 to $5.5 \%$. The accelerated response of ductility to $\mathrm{Ta}$ concentration made it necessary to prepare and test more alloys that ranged from 12.3 to $13.8 \%$ in Ta contents. Alloys $A_{10} B_{10}$ to $A_{12} B_{12}$ were prepared so that the Ta concentration was increased in increments of $0.5 \mathrm{gm} / 100 \mathrm{gm}$ of the alloy base. The elongation values of the latter alloys supported the sudden reduction in ductility when the $\mathrm{Ta}$ was increased from 12.3 to $13.8 \%$. When the elongation was plotted as a function of Ta concentration (Fig 3), the accelerated response was a step $(B)$ in the curve. Figure 3 indicates that there is another step that corresponds to $\mathrm{Ta}$ concentrations ranging from 7.4 to $9.1 \%$. Because the mechanical properties of the alloys that had these concentrations of $\mathrm{Ta}$ did not fulfill those required for a dental alloy, further investigation of the latter range was not necessary.

YIELD STRENGTH.- The mean values of the $0.2 \%$ offset yield strength of the prepared alloys, together with the values for 95\% confidence limits, are shown in a bar graph (Fig. 4). The yield strength increased with $\mathrm{Ta}$ concentration from $44 \times 10^{3} \mathrm{psi}$ for the Ta-free alloy $A_{1} B_{1}$ to $108 \times 10^{3} \mathrm{psi}$ for alloy $A_{15} B_{15}$ that contained $16.7 \% \mathrm{Ta}$. As with elongation, the value of the yield strength increased rapidly in the $\mathrm{Ta}$ range from 12.3 to $13.8 \%$; this is represented by alloys $A_{9} B_{9}$ to $A_{13} B_{13}$. The yield strength increased from $80.4 \times 10^{3}$ psi for the former alloy to $98.8 \times 10^{3}$ psi for the latter. At Ta concentrations of less than $12.3 \%$,

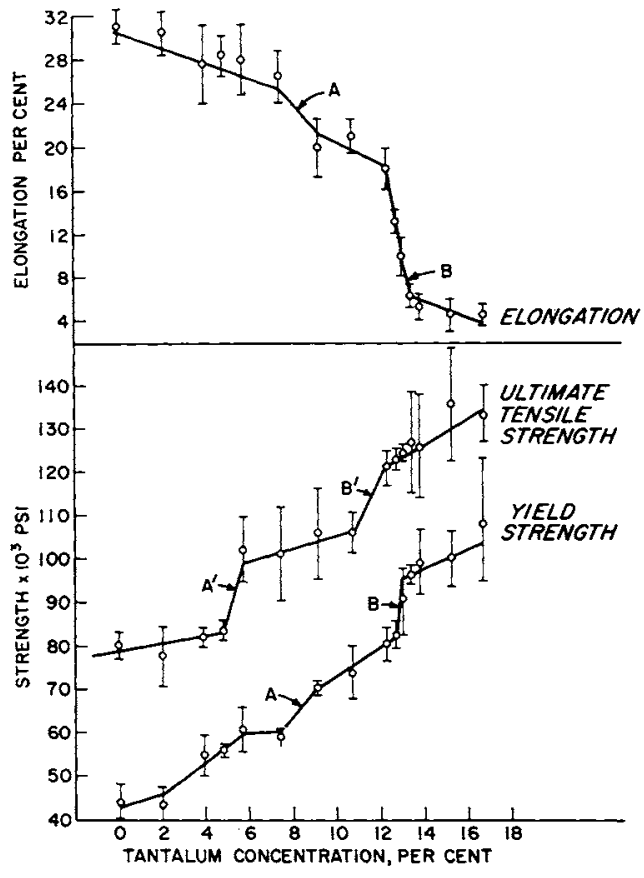

FIG 3.-Tensile properties of prepared alloys as a function of Ta concentration.

the increase in the yield strength was almost 5,000 psi; this increase was caused by an increase of the Ta concentration of $2 \mathrm{gm} / 100 \mathrm{gm}$ of the alloy base. The yield strength vs $\mathrm{Ta}$ concentration is plotted in Figure 4, which shows a step $(B)$ in the curve.

The curves in Figure 3 represent the yield strength and the elongation as a function of $\mathrm{Ta}$ concentration; the accelerated response of both properties to $\mathrm{Ta}$ addition occured in the same region. The response of the elongation ( 18 to $5.5 \%$ ) was greater than that of the yield strength $\left(80 \times 10^{3}\right.$, to $98 \times 10^{3} \mathrm{psi}$ ).

Ultimate TENSIle STRENGTH (UTS).The results of the tests for the UTS were treated in a manner similar to those for the yield strength and they are plotted as a bar graph in Figure 5. The UTS increased from $80 \times 3$ to $133.3 \times 10^{3}$ psi as the $\mathrm{Ta}$ concentration was changed from $0 \%\left(A_{1} B_{1}\right)$ to $16.7 \%\left(A_{15} B_{15}\right)$. As in the examples of yield strength and elongation, a line that connects the means represents the UTS; this line has "jump" in it that is marked $\left(B^{\prime}\right)$ in Figure 3. This change occurred when the Ta concentration was varied from 


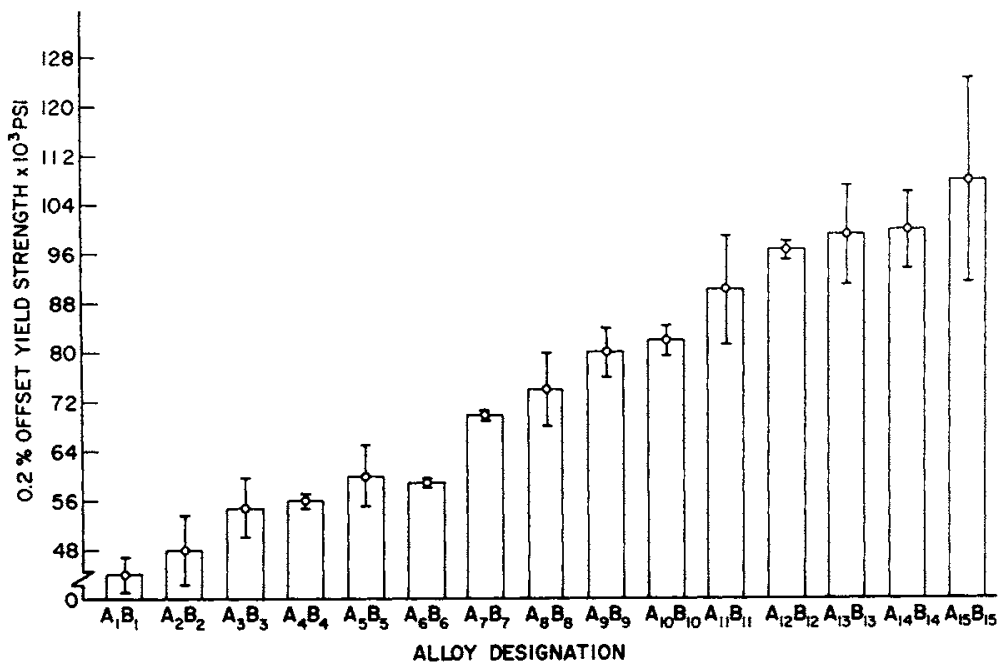

FIG 4.-Effect of alloy composition on yield strength.

10.7 to $12.3 \%$, which is lower than that of yield strength and elongation.

MODULUS OF ELASTICITY.-The mean values and confidence limits for the modulus of elasticity are shown in Figure 6 . The modulus of elasticity increased from $26.4 \times$ $10^{6} \mathrm{psi}$ for the alloy base $\left(A_{1} B_{1}\right)$ that contained no $\mathrm{Ta}$ to $32.8 \times 10^{6} \mathrm{psi}$ for the alloy $A_{15} B_{15}$ that contained $16.7 \%$ Ta.

MICROHARDNESS. - The microhardness of the alloys is shown in Figure 7. Each value is the mean of ten readings. Hardness in- creased from KHN 232 for alloy $A_{1} B_{1}$ that had no Ta to KHN 373 for alloy $A_{14} B_{14}$ that had $14.2 \% \mathrm{Ta}$.

\section{Discussion}

The Co-Ta binary phase diagram was determined by Korchynsky and Fountain. ${ }^{5}$ They found that the first precipitate that formed with age was $\alpha-\mathrm{Co}_{3} \mathrm{Ta}$. It was indicated in part I of this study that Ta is characterized by a large electron hole number $\left(N_{v}\right.$ $=5.66$ ) ; unless it is precipitated from the

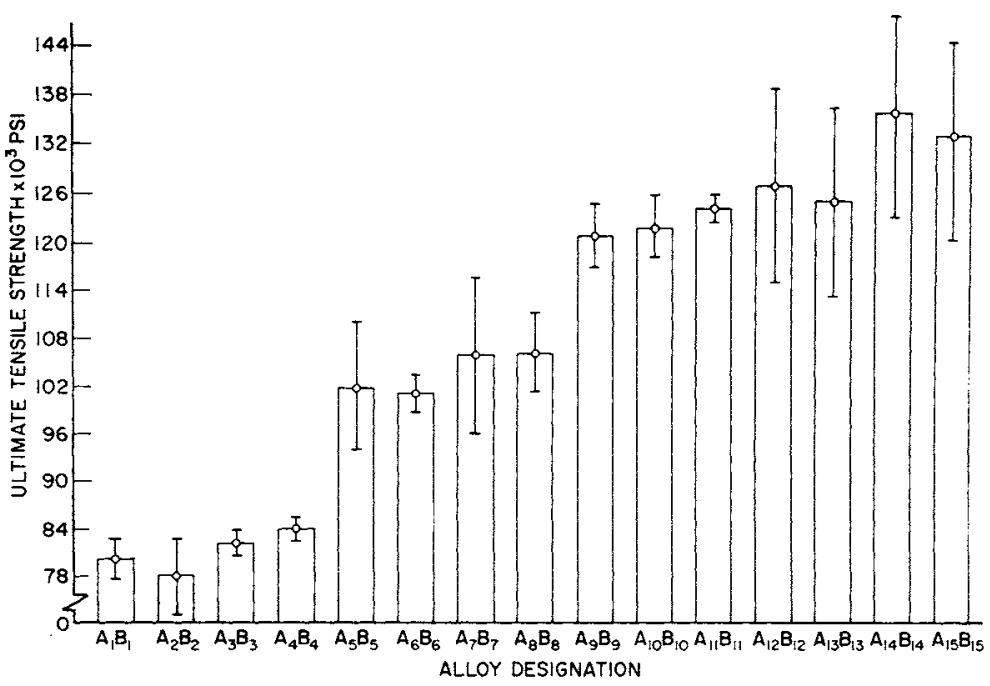

FIG 5.--Effect of alloy composition on ultimate tensile strength. 


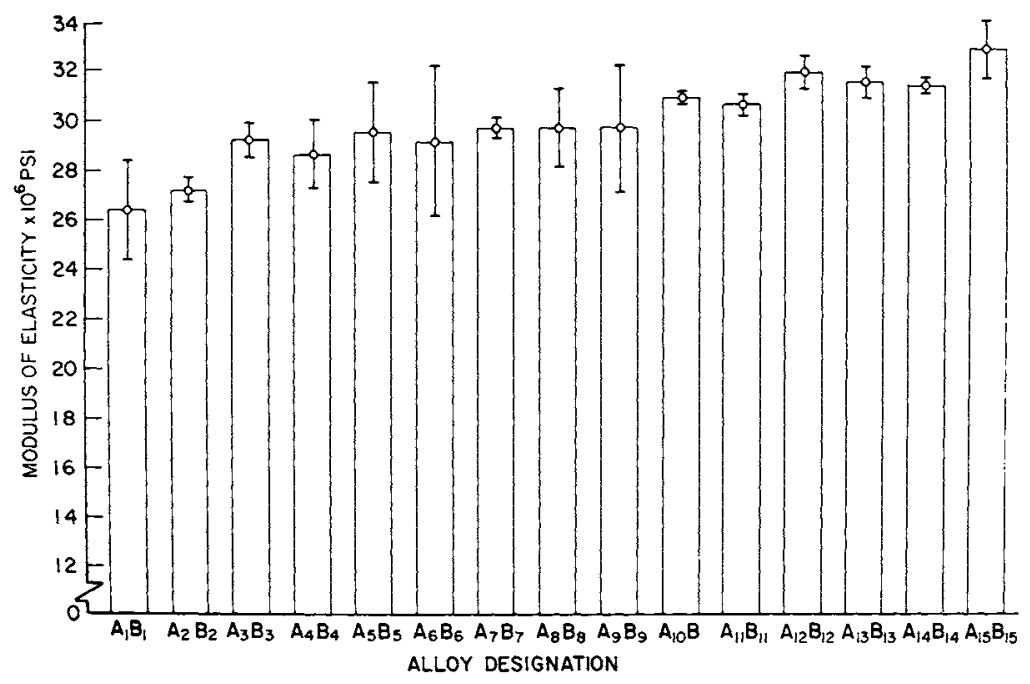

FIG 6.-Effect of alloy composition on modulus of elasticity.

matrix, the formation of the embrittling $\sigma$ phase will result.

Thus, the response of the tensile properties to $\mathrm{Ta}$ concentration indicates that there are two rapid rates of change in the mechanical properties at certain ranges of Ta concentration. These regions are marked $A$ and $B$ in Figure 3 . The rapid rate of change $(A)$ is preceeded by a slower rate of change. This may be caused by the solid solution hardening effect of Ta (atomic radius, $1.46 \mathrm{~A}$ ) on the ternary alloy matrix (average atomic radius, $1.26 \mathrm{~A}$ ). The rapid rate of change $(A)$ may be caused by the formation of the intermetallic compound $\mathrm{Co}_{3} \mathrm{Ta}$ that precipitated coherently with the face-centered cubic $\mathrm{Co}-\mathrm{Cr}-\mathrm{Ni}$ phase, $\alpha .^{1}$

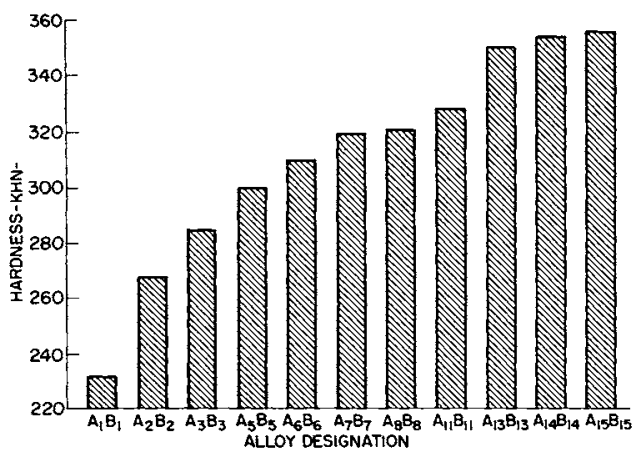

Fig 7.-Effect of alloy composition on hardness.
The second rapid rate of change (marked $B$ ) may be the result of the formation of $\sigma$ phase at high concentrations of Ta.

It was proposed in part I of this study that intermetallic compounds of $\mathrm{Ta}$ might increase the yield strength more efficiently than reduce the ductility; this is an advantageous discrepancy for dental applications. This effect can be demonstrated by a comparison of the reduction in ductility and the increase in the yield strength as Ta was increased from $0 \%$ for alloy $A_{1} B_{1}$ to $7.4 \%$ for alloy $A_{6} B_{6}$. The data in Figures 3 and 5 show that the addition of $7.4 \%$ Ta to the ternary alloy caused the elongation to decrease from 31 to $27 \%$ (a decrease of $12 \%$ of the original value). The same concentration of $\mathrm{Ta}$ caused the yield strength to increase from $41 \times 10^{3}$ to $61 \times 10^{3} \mathrm{psi}$ (an increase of $50 \%$ of the original value). The addition of $7.4 \%$ Ta improved the yield strength significantly and caused a mild loss in ductility. This favorable effect is caused by the fineness of the coherent intermetallic compound and the effect of $\mathrm{Ta}$ of raising the stacking fault energy (SFE) of the alloy. A higher SFE produces stability in the ductile FCC $\alpha$ phase; its concentration increased in the matrix as was discussed in part I. ${ }^{1}$

The data in Figure 4 demonstrate that the $\sigma$ phase has an embrittling effect on Co alloys. ${ }^{6}$ The rapid change (marked $B$ ) 
occurred when the concentration of Ta was varied from 12.3 to $13.4 \%$. This increase in $\mathrm{Ta}$ concentration caused a decrease in ductility from 18 to $6 \%$ elongation, ie, a loss of $66 \%$ of the original value. The same increase in $\mathrm{Ta}$ concentration caused the yield strength to increase from 80 to $95 \times$ $10^{3} \mathrm{psi}$, ie an increase of $18 \%$ of the original value.

In summary, when the ratio of the rate of change of ductility to the rate of change of yield strength is considered, the $\sigma$ phase has the opposite effect of the $\mathrm{Co}_{3} \mathrm{Ta}$ phase.

The results of the tests of the modulus of elasticity (Fig 6), indicate an increase from 26.4 to $32.8 \times 10^{6} \mathrm{psi}$. An increase in the value of the modulus of elasticity indicates that the compositional variation caused tension of the matrix lattice of more than $1 \% .{ }^{7}$ The FCC matrix $\alpha$ phase has a lattice constant of $a=3.545 \mathrm{~A}$ and it can be stretched by the formation of $\alpha-\mathrm{Co}_{3} \mathrm{Ta}$; this is a simple cubic structure and it has a lattice constant of $a=3.647 \mathrm{~A}^{8}$ The simple cubic structure becomes coherent with the face-centered cubic structure in an attempt to stretch the lattice of the latter to match its own.

\section{Conclusions}

The experimental evidence of this investigation leads to the following conclusions: Alloys that are stronger and more ductile than conventional dental alloys can be prepared if the alloy design is determined by theoretical considerations. ${ }^{1} \mathrm{Ta}$ is an efficient element that strengthens $\mathrm{Co}-\mathrm{Cr}-\mathrm{Ni}$ alloys. The use of $\mathrm{Ta}$ should be determined by average electron hole number $\left(\bar{N}_{v}\right)$ considerations. Excessive use of $\mathrm{Ta}$ embrittles the alloy through the formation of the $\sigma$ phase. The formation of intermetallic compounds of $\mathrm{Ta}$ provides a fast rate of response of the yield strength and a slow rate of response of the ductility; this produces strong and ductile alloys.

\section{References}

1. Mohammed, H., and Asgar, K.: A New Dental Superalloy System: I. Theory and Alloy Design, J Dent Res 52:136-144, 1973.

2. Asgar, K.; TeChow, B.O.; Allan, F.C.; and SutFin, L.V.: Effect of Casting Condition on Physical Properties of Some Experimental Partial Denture Alloys, J Biomed Mater Res 3:409-423, 1969.

3. Guide to Dental Materials and Devices, 5th ed, Chicago: American Dental Association, 1970-1971, pp 171-173.

4. DiXon, W.J., and MASSEY, F.J., JR.: Introduction to Statistical Analysis, 3rd ed, New York: McGraw-Hill, 1969, p 77.

5. KORCHYNSKY, M., and FounTAIN, R.W.: Precipitation Phenomena in Cobalt-Tantalum Alloys, Trans AIME 215:1033, 1959.

6. Cabalt (monograph), Belgium: Centre D'information Du Cobalt, 1960.

7. VAN Vlack, L.H.: Elements of Material Science, 2nd ed, Massachusetts: AddisonWesley, 1964.

8. Drapier, J.M.; DE Brouwer, J.L.; and Coutsouradis, D.: Refractory Metals and Intermetallic Precipitates in Cobalt Chromium Alloys, Cobalt 27:59, 1965. 